\title{
Water up-take in fuel pellets studied by Dynamic Vapour Sorption (DVS) analysis and its potential role in self-heating during storage
}

\author{
Calle Nilsson ${ }^{1} \cdot$ Henrik Ramebäck $^{2} \cdot$ Callum Hill $^{3,4} \cdot$ Mehrdad Arshadi $^{1}$ (D)
}

Received: 5 December 2017 / Published online: 11 October 2018

(c) The Author(s) 2018

\begin{abstract}
The self-heating of wood fuel pellets is a well-recognised problem causing fire incidents in the storage of the pellets as well as severe intoxication of workers by elevated carbon monoxide and carbon dioxide levels and oxygen depletion. Possible factors contributing to the self-heating are considered to be autoxidation and microbiological activity, while the role and contribution to the temperature rise caused by the heat of condensation from water vapour condensing during fast changes in the relative air humidity is less investigated. Using Dynamic Vapour Sorption, the water uptake was measured at $25{ }^{\circ} \mathrm{C}$ when increasing the RH from 40 to $80 \%$ using 35 fuel pellet samples covering a broad variation in pellet raw materials and process equipment found in Europe (both pilot and industrial scale). The equilibrium total water uptake and speed of the uptake were determined. Total water uptake was $4.56 \%$ (range 3.69-6.86\%) with no systematic difference found related to the scale of production (industry as compared to pilot plant). In addition, the variations within larger groups of raw material (pine, spruce and pine/spruce mixtures) were relatively small, and the mean water uptake did not differ significantly between these groups. An estimation of the overall potential heat release (when raising the RH\% from 40 to $80 \%$ ) made from the experimental results, taking the early fast water uptake process into consideration ( $2 \mathrm{~h}$ counting for half the total uptake), showed that a heat release of $47 \mathrm{~kJ} / \mathrm{kg}$ of pellets (range $12-63 \mathrm{~kJ} / \mathrm{kg}$ ) and a potential temperature increase of $45^{\circ} \mathrm{C}$ is possible. This estimation clearly demonstrates that the heat of condensation released during water condensation in a pellets silo or in a pellets pile should be expected to be a major contributing factor to initiating temperature rise incidents. In addition, such a temperature increase is expected to assist the initiation of, and to increase the speed of autoxidation of fatty acids and other compounds in the material that will further contribute to a temperature rise. Thus, the results in this study have the potential to improve the basis for modelling the self-heating process in pellet silos/storage and to predict the status of a certain pellet batch by presenting a broad basis for expected variation in the important parameters (specific heat capacity $C_{\boldsymbol{P}}$ and thermal conductivity $\lambda_{\text {eff }}$ ) influencing the process, and thus aid in taking preventive actions like venting or shifting the pellets to another silo/pile to reduce risk for self-heating and possible fire.
\end{abstract}

\section{Introduction}

Mehrdad Arshadi

mehrdad.arshadi@slu.se

1 Department of Forest Biomaterials and Technology, Swedish University of Agricultural Sciences (SLU), 90183 Umeå, Sweden

2 Swedish Defence Research Agency, CBRN Defence and Security (FOI), 90182 Umeå, Sweden

3 Norwegian Institute of Bioeconomy Research, PO Box 115, 1431 Ås, Norway

4 Department of Architecture and Civil Engineering, University of Bath, Bath BA2 7AY, UK

Spontaneous self-heating in wood bio-fuel pellets during storage and transport (e.g., in silos and during bulk transportation by ship) has been reported to cause fire incidents, oxygen depletion and formation of carbon monoxide, carbon dioxide and volatile compounds (Fan and Bi 2013; Kuang et al. 2008, 2009a, b; Pa and Bi 2010; Koppejan et al. 2013; Ashman et al. 2018). Apart from the economic consequences of these large fires, the oxygen depletion and emission of toxic volatiles have caused several accidental deaths and severe incidents among workers exposed (Granström 2009, 2010; Hyttinen et al. 2010; Rupar-Gadd 2006; Arshadi et al. 2009; Arshadi and Gref 2005). The reason for self-heating is generally attributed to autoxidation and/or microbiological 
activity (Larsson et al. 2012; Stratev et al. 2011; Arshadi et al. 2009; Arshadi and Gref 2005; Hemingway et al. 1971).

Autoxidation of fatty acids (triglycerides) is a well-known phenomenon resulting in a complex mixture of components such as shorter fatty acids, aldehydes (saturated and unsaturated) as well as carbon monoxide and dioxide (Svedberg et al. 2004, 2008, 2009). The fatty acid content in wood pellets is generally in the range of $1-2 \%(w / w)$. The autoxidation being an exothermic chain radical reaction can be considered a significant contributing factor in the self-heating process (Blomqvist and Persson 2003, 2008).

When it comes to the role of microbial activity (that is found, for example, in outdoor storage of wood chips for paper pulp production) (Jirjis 1995) this is less likely to be a major contributor to the self-heating of fuel pellets in storage since the material is relatively dry (wood pellets have a moisture content (MC) of 5-10\% w.b.) (Obernberger and Thek 2010; Stelte et al. 2012). In addition, the pelleting process heats the material to $90-150{ }^{\circ} \mathrm{C}$ (Obernberger and Thek 2010), a temperature that is likely to kill most of the microorganisms that might be found in the raw material (Obernberger and Thek 2010; Filbakk et al. 2011).

However, heat of condensation/sorption and the role of water uptake caused by condensation during changes in relative air humidity seem to have received less attention when it comes to the area of storage of biofuel pellets. The self-heating of cellulose materials (wood, particleboard, etc.) has been discussed earlier in the literature. The adsorption rate of water vapour and temperature change of coal directly during coal storage and transportation have recently been investigated (Miura 2016). It has been shown that the heat released by an increase of a few percent in the moisture content in lignocellulosic material can raise the temperature of the material to a range where the oxidation rate increases sufficiently to lead to onset of carbonisation in the material and in the end possible auto-ignition (Back 1981/82; Back and Johanson 1990; Korber et al. 2010). Dynamic Vapour Sorption (DVS) is a technique based on the gravimetric determination of vapour (mostly water vapour) interactions with a sample. By varying the water vapour concentration (i.e., relative humidity, $\mathrm{RH} \%$ ) surrounding a sample and measuring the change in mass it produces, the rate of water sorption (adsorption and absorption) and quantity of sorbed water can be measured. This technique has been used, for example, in studies on wood behaviour (Xie et al. 2011a, b; Hill et al. 2010).

In order to estimate the role of water condensation as a contributing factor in these self-heating incidents, knowledge of how water vapour interacts with fuel pellets is required. This will contribute to vital information on estimating the role of heat of condensation in fuel-pellet storage facilities and the possible increase in temperature and self-heating incidents.
The main objective of the present study was to gain an estimation of the potential contribution to self-heating of fuel pellets caused by water condensation resulting from a fast change in the relative air humidity. Dynamic Vapour Sorption (DVS) experiments were used (during a change in RH from 40 to $80 \%$ ) in order to measure the amount and speed of water uptake. Using the data, the heat of condensation formed and a maximum theoretical temperature rise were calculated. Further, the results are expected to aid in understanding the potential contribution of air humidity changes to self-heating incidents in pellet storages.

\section{Materials and methods}

\subsection{Samples}

When selecting pellet samples for the project, 35 batches from three pellet types generally commercially available in Europe were chosen for the study; (i) pellets that represent the current market, (ii) pellets that are expected to have an increased relevance in the future, and (ii) pellets, which can directly be related to self-heating and off-gassing incidents. The samples were collected and distributed as a part of the EU project SafePellets (Safepellets project, European project, grant agreement number 287,026). Samples used for the DVS analyses are listed in Table 1.

All samples (ca $5 \mathrm{~kg}$ each) were sealed in $15 \mathrm{~L}$ airtight polyethylene bags after production as in Table 1 and transported to the laboratory within 1-2 days from bagging. The samples were stored in the laboratory at $4{ }^{\circ} \mathrm{C}$ until DVS analysis. No binders were used in any of the batches. Batch number 34 was not included in the calculation since it was a new production of torrefied pellets as batch number 20 but the batch was not homogenous with high percent of fines and therefore, omitted from the calculations.

\subsection{Dynamic vapour sorption analysis}

\subsubsection{Sample preparation}

Samples (small single pellets, ca. $0.190 \mathrm{~g}$, relative standard deviation (RSD) 7.5\%) were randomly selected from the larger bagged sample batches described in Sect. 2.1 (Table 1). The samples were prepared for DVS analysis by conditioning in a constant humidity cabinet (Climacell 111, MMM-Medcenter Einrichtungen $\mathrm{GmbH}$, Germany) at $40 \% \mathrm{RH}$ and $25^{\circ} \mathrm{C}$ for a minimum of $96 \mathrm{~h}$. Triple samples were run to estimate the method variation using pellets from Batches 8 and 12 . 
Table 1 Composition and density of pellets of the samples used in the study $(\mathrm{CP}=$ Commercial plant, $\mathrm{RP}=\mathrm{Research}$ plant $)$

\begin{tabular}{|c|c|c|c|}
\hline Batch & Pellet raw material and treatment at production & Pelletizing Plant & $\begin{array}{l}\text { Density of } \\
\text { pellets }(\mathrm{kg} / \\
\left.\mathrm{m}^{3}\right)\end{array}$ \\
\hline 1 & Pine $100 \%$. Ground material stored 4 days in big bag at $20^{\circ} \mathrm{C}$ before pelletizing & German, RP & 1254 \\
\hline 2 & Spruce $100 \%$. Ground material stored 8 days in big bag at $20^{\circ} \mathrm{C}$ before pelletizing & German, RP & 1258 \\
\hline 3 & Pine $100 \%$. Pelletized immediately after grinding & German, RP & 1254 \\
\hline 4 & Spruce $100 \%$. Pelletized immediately after grinding & German, RP & 1258 \\
\hline 5 & Pine $100 \%$. Sample from ordinary production & German, CP 1 & 1213 \\
\hline 6 & Spruce $80 \% /$ Pine $20 \%$. Sample straight from ordinary production & Swedish, CP 1 & 1217 \\
\hline 7 & $83 \%$ straw, $11 \%$ seed residue, $6 \%$ spruce. Sample straight from ordinary production & Danish, CP 1 & 1183 \\
\hline 8 & Spruce $100 \%$. Sample straight from ordinary production & German, CP 2 & 1180 \\
\hline 9 & Pine $40 \% /$ Spruce $60 \%$. Sample from ordinary production & Swedish, CP 2 & 1212 \\
\hline 10 & Pine $60 \% /$ Spruce $40 \%$. Sample from ordinary production & Swedish CP 3 & 1225 \\
\hline 11 & Eucalyptus $100 \%$. Stored one year at the company & Spain CP 1 & 1211 \\
\hline 12 & Pine $50 \% /$ Spruce $50 \%$. Sample straight from ordinary production & Swedish CP 4 & 1201 \\
\hline 13 & Vine pruning $50 \% /$ vine pomace $50 \%$ & German RP & 1324 \\
\hline 14 & Pine $100 \%, \mathrm{scCO}_{2}$ extracted (extracted at York, Swedish raw material), run 1 & German RP & 1191 \\
\hline 15 & Pine $100 \%$ & Austrian RP & 1256 \\
\hline 16 & Pine $100 \%, \mathrm{RP}$ (same raw material as in Batch 15 but different equipment with pelletizing) & German RP & 1185 \\
\hline 17 & Straw pellets $(100 \%)$. Stored in a flat storage for 6 months before delivery & Danish CP 2 & 1116 \\
\hline 18 & Spruce $80 \% /$ Pine $20 \%$ - mixed pellets & German CP 3 & 1182 \\
\hline 19 & Pine $100 \%$, torrefied at $308{ }^{\circ} \mathrm{C}, 12 \mathrm{~min}$, pelletized after cooling & Swedish RP & 1259 \\
\hline 20 & Pine $100 \%$, torrefied at $315^{\circ} \mathrm{C}, 12 \mathrm{~min}$, pelletized after cooling & Swedish RP & 1177 \\
\hline 21 & Obtained from pellet company after fire accident & Swedish CP 3 & N/A \\
\hline 22 & Eucalyptus $100 \%$ & German CP 4 & 1290 \\
\hline 23 & Pine $100 \%$, reference to Batches $24,25,27$, pelletized after cooling & Swedish RP & 1243 \\
\hline 24 & Pine $100 \%$, with TBHQ as antioxidant, pelletized after cooling & Swedish RP & 1232 \\
\hline 25 & Pine $100 \%$, with PG as antioxidant, pelletized after cooling & Swedish RP & 1225 \\
\hline 26 & $75 \%$ pine, $25 \%$ fir and larch & Danish CP 3 & 1274 \\
\hline 27 & Pine $95 \%$, with $5 \%$ spruce bark & Swedish RP & 1248 \\
\hline 28 & Spruce $100 \%$. Flat storage trial in Denmark, sampling after 1 week & Danish CP & 1252 \\
\hline 29 & Spruce $100 \%$. Flat storage trial in Denmark, sampling right after production & Danish CP & 1250 \\
\hline 30 & Obtained from pellet company after a fire accident & German CP 5 & 1225 \\
\hline 31 & $100 \%$ pine, reference to Batch 14 & German RP & 1270 \\
\hline 32 & Pine $100 \%, \mathrm{scCO}_{2}$ extracted (extracted at York, Swedish raw material, run 2) Attard et al. (2016) & German RP & 1238 \\
\hline 33 & Reference to Batch 32. Attard et al. (2016) & German RP & 1139 \\
\hline 35 & Pine $100 \%$, with $0.5 \%$ additive & Swedish RP & 1137 \\
\hline 36 & Reference to Batch 35 & Swedish RP & 1159 \\
\hline
\end{tabular}

Density given as the mean pellet density calculated from 20 randomly chosen pellets from each batch respectively (Larsson and Samuelsson 2017)

\subsubsection{Instrument}

The instrument used was a Dynamic Vapour System instrument (DVS), model Advantage ET2 (Surface Measurement Systems, UK). The instrument has a sensitivity of $1.0 \mu \mathrm{g}$, dynamic range of $1 \mathrm{~g}$, sample mass $(\max )$ of $5 \mathrm{~g}$, a relative humidity $(\mathrm{RH})$ range of $0-98 \%+/-0.5 \%$ and a temperature range of $20-85^{\circ} \mathrm{C}$. The DVS instrument was operated using the following run-cycle (see Fig. 1):
1. Equilibration of sample at $\mathrm{RH} 40 \%: 5 \mathrm{~h}$ at $25{ }^{\circ} \mathrm{C}$

2. Increase of RH to $80 \%$ which is held for $13 \mathrm{~h}$

3. Drying step $5 \mathrm{~h}$ at $105{ }^{\circ} \mathrm{C}$ and $\mathrm{RH} 0 \%$ in order to determine the dry matter of the sample.

Due to the long analysis time for each sample, the same instrumental parameters were used during the whole study. This does not imply that a variation in conditions would not be of interest. On the contrary, from the results obtained in 


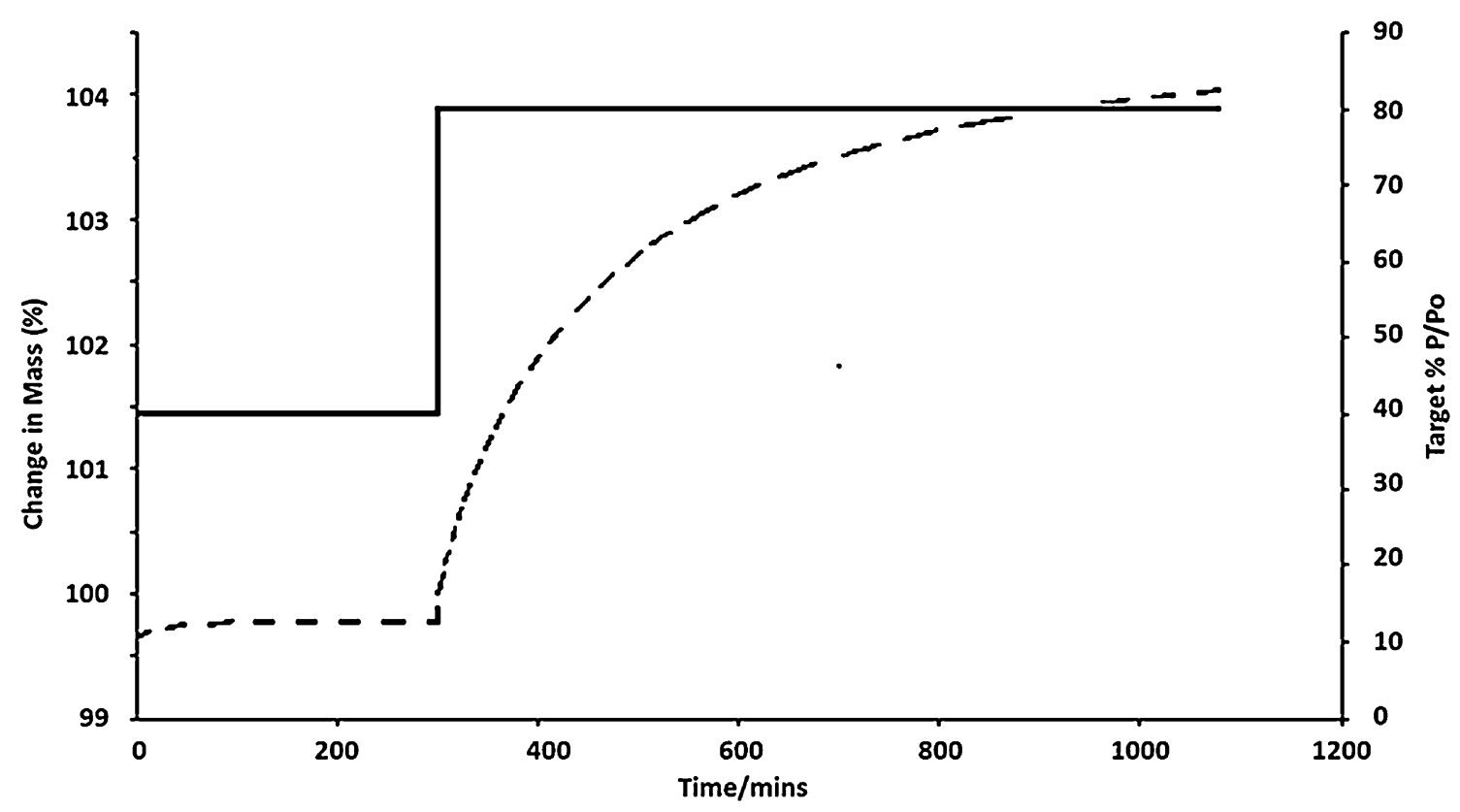

Fig. 1 DVS data registration from Batch 2. Solid line shows the DVS operating program. Dashed line shows registered weight-gain due to water uptake

this study, it is expected that additional valuable information can be gathered by DVS applying other sets of parameters.

\subsection{Data collection and interpretation}

For data collection and dm/dt calculations, the DVS instrument software was used. The weight-gain was measured to about $85-90 \%$ of the maximum weight-gain under the conditions used (13 h at RH 80\%) with a sampling frequency of 3/min. Equilibrium water content at RH $80 \%$ was estimated by extrapolation to constant weight (more than 6 consecutive data points showing the same weight in $\mathrm{g}$ with 6 decimals) using the Excel Solver Ad-in software (Microsoft Office). The Parallel Exponential Kinetics (PEK) model was applied to the modelling (Hill et al. 2010). The first 8 min of registration after the start of the RH $80 \%$ step were not taken into account since conditions are not stable then.

\section{Results and discussion}

\subsection{General considerations and basis for interpretation}

The experimental conditions in this study were chosen so as to model a fast change in the air RH in a pellet silo/storage. Starting conditions were set to an air RH of $40 \%$ at $25{ }^{\circ} \mathrm{C}$, which is a typical lower air humidity level. The change to RH $80 \%$ was chosen to simulate, for example, a late summer/autumn situation where the $\mathrm{RH} \%$ often increases fairly quickly (to 70-90\%) at the end of the day (Graham et al. 2017). In earlier studies typical temperatures during storage of fuel pellets were found to be in the range of $25-70{ }^{\circ} \mathrm{C}$ (Kuang et al. 2009a; Graham et al. 2016) and experiences from commercial silos (Larsson et al. 2012) verify these observations.

For modelling of the water vapour up-take process, the parallel exponential kinetics (PEK) model (Hill et al. 2010) was applied to the DVS data collected. It comprises two exponential functions describing two different processes that contribute to the total uptake as discussed by Hill et al. (2010). Thus, what is registered in an experiment by DVS is the sum of the two processes.

The model parameters were calculated by minimizing the weighted error square sum:

$$
\begin{aligned}
\mathrm{MC}= & \mathrm{MC}_{0}+\mathrm{MC}_{1}\left[1-\exp \left(-t / t_{1}\right)\right] \\
& +\mathrm{MC}_{2}\left[1-\exp \left(-t / t_{2}\right)\right]
\end{aligned}
$$

MC Mass of water absorbed by the sample at infinite time (g), i.e. moisture content at infinite time. $\mathrm{MC}_{0}$ Mass of sample at time 0 (i.e. when the RH $80 \%$ step starts), set to $0 \mathrm{~g}$. $\mathrm{MC}_{1}$ Portion of mass of absorbed water originating from fast process $(\mathrm{g}) . \mathrm{MC}_{2}$ Portion of mass of absorbed water originating from slow process $(\mathrm{g}) . \mathrm{t}$ Time in process $(\mathrm{min}) . \mathrm{t}_{1}, \mathrm{t}_{2}$ Characteristic times for respective process (equation) ( $\mathrm{min}$ ).

The data from the analysis allows measuring or calculating the following parameters:

- Total water uptake for the pellet batch (\%) 
- Speed of water uptake (i.e. $\mathrm{dm} / \mathrm{dt}$ )

- Calculated values of the parameters in the model equation that reflect the properties of water uptake for each batch individually (MC1 and MC2).

\subsection{Measured data and method repeatability}

It was observed that it is not reasonable to follow the water up-take process to equilibrium, which would take about 2 days (on average and maximum 6 days) as estimated by the Solver program. A typical result from a DVS run (Batch 2 ) is shown in Fig. 1. The chosen length of the RH $80 \%$ step $(13 \mathrm{~h})$ which is a reasonable time for practical application allows covering the weight-gain to about $90 \%$ of its maximum (infinite) weight-gain at the conditions used. This means that modelling of the remaining part of the process is required in order to determine the total weight gain for a specific pellet batch under the conditions used. The water uptake was measured when increasing the RH from 40 to $80 \%$ (as described above). The equilibrium water uptake was extrapolated to the time where the weight $(\mathrm{g})$ remained constant (6 decimals) using the PEK model for estimation of the "infinite" water uptake. This modelling and extrapolation were made using the Solver program, and an overview of the DVS results are presented in Table 2. The calculated time when equilibrium water uptake was reached was $3000 \mathrm{~min}$ (mean) from start of the RH $80 \%$ step, but varied between 1800 and $5800 \mathrm{~min}$ (RSD 47\%), which is also reflected in the differences observed in the water uptake rate as expressed by the derivative $\mathrm{dm} / \mathrm{dt}$ (Table 2 ).

The method repeatability was determined by running two of the batches (Batch 8 and 12) in triplicate. The repeatability in total water uptake was $2.4 \%$ and $2.8 \%$ RSD of the mean (relative standard deviation of the mean) for the two batches respectively. The repeatability for the derivative of the water uptake was observed and found at 10,30 and $60 \mathrm{~min}$ to be $(3.7 ; 2.5),(3.7 ; 1.8)$ and $(4.5 ; 2.7)$ for the two batches, respectively. This was regarded as adequate taking the expected batch sample homogeneity and the small sample size possible to use in the DVS experiments into consideration.

\section{3 "Infinite" water uptake-influences of raw material and production}

No systematic difference in total water up-take that was related to the production in industry as compared to pilot plants was found using T-test (Table 3 ). In addition, the variations within the larger groups of raw material (pine, spruce and pine/spruce mixtures) were relatively small (Table 3 ), and the mean water uptake did not differ significantly between these groups (T-test). However, batches made from wheat straw, wine prunings/pomace and torrefied pine did differ more from the rest (Table 3), although the number of samples from these groups was small.

\subsection{Modelling of the water up-take process}

Modelling of the process using the Solver software generated parameters for the fitted PEK equation with a low or excellently low weighted error square sum (ESS) (Table 2). The equation and fitted model are shown in Fig. 2 for one of the samples. The PEK model, describing two different processes that contribute to the total uptake, are explained by Popescu et al. (2015) as a fast process being due to a physical diffusion process and a slow process as being due to a relaxation-limited process.

When separating the two equation components in the data of this study, it is observed (Fig. 2) that the fast process contributed less than the slow process to the total water uptake in all samples. However, the fast process has the largest influence in the first $2 \mathrm{~h}$ of water uptake and is thus likely to contribute most to a self-heating situation due to the quick rise in water uptake the first few hours after a change in $\mathrm{RH} \%$ during pellet storage.

As discussed by Xie et al. (2011a), the reason for the differences in the allocation of moisture to the fast and slow processes is not fully revealed. However, the fast kinetic process was suggested to be related to a fast moisture sorption at "external" surfaces and "amorphous" regions, whereas the slow kinetic process was related to sorption onto the "inner" surfaces and "crystallites" (Morton and Hearle 1997; Okubayashi et al. 2004).

\subsection{Rate of water up-take}

The derivative for the water up-take over time is calculated by the software in the DVS instrument and is available for all data points. For the interpretation of the data and comparison of the various pellet batches, $\mathrm{dm} / \mathrm{dt}$ at 10,30 and $60 \mathrm{~min}$ were used. The reason for that choice is that the initial water uptake is fairly fast and is expected to contribute to the fast temperature rise observed in connection with the initiation of fire and heating incidents in pellets silos/storages (Larsson et al. 2012).

In Fig. 3, the water up-take rate $(\mathrm{dm} / \mathrm{dt})$ over time for four different batches is compared. These examples illustrate the wide variation in uptake rate, despite the total water uptake being almost the same for three of these samples. The reason for this behaviour might reflect differences in production parameters (e.g., pilot plant and industry scale production) but requires additional research in order to be explained. The production process in the pellet industry uses higher drying temperatures and a larger feedstock flow through the pellets press, also resulting in a higher temperature in the pellet die due to the continuous 
Table 2 Overview of the results from DVS measurements

\begin{tabular}{|c|c|c|c|c|c|c|c|c|c|}
\hline \multirow[t]{2}{*}{ Batch } & \multirow{2}{*}{$\begin{array}{l}\text { "Infinite" water } \\
\text { uptake }(\%)\end{array}$} & \multicolumn{5}{|c|}{ Solver solution parameters } & \multicolumn{3}{|c|}{$\mathrm{dm} / \mathrm{dt}(\mathrm{g} / \mathrm{min})$} \\
\hline & & $\begin{array}{l}\text { Water uptake } \\
(\%) \text { after } 2 \mathrm{~h}\end{array}$ & $\mathrm{MC} 1$ & $\mathrm{MC} 2$ & $\mathrm{t} 1(\min )$ & $\mathrm{t} 2(\min )$ & At $10 \mathrm{~min}$ & At $30 \mathrm{~min}$ & At $60 \mathrm{~min}$ \\
\hline 1 & 4.50 & 1.72 & 0.00184 & 0.00756 & 49.37 & 405.7 & 0.02954 & 0.01839 & 0.01306 \\
\hline 2 & 4.32 & 2.10 & 0.00339 & 0.00533 & 78.46 & 342.9 & 0.03507 & 0.02343 & 0.01636 \\
\hline 3 & 3.91 & 2.02 & 0.00189 & 0.00483 & 51.13 & 260.4 & 0.03650 & 0.02246 & 0.01541 \\
\hline 4 & 4.62 & 2.37 & 0.00194 & 0.00628 & 46.33 & 247.7 & 0.03978 & 0.02654 & 0.01845 \\
\hline 5 & 4.90 & 2.38 & 0.00254 & 0.00625 & 78.90 & 260.5 & 0.03538 & 0.02552 & 0.01943 \\
\hline 6 & 4.20 & 2.32 & 0.00222 & 0.00609 & 46.40 & 221.2 & 0.04001 & 0.02689 & 0.01777 \\
\hline 7 & 5.77 & 2.73 & 0.00250 & 0.00930 & 63.90 & 256.7 & 0.03986 & 0.02957 & 0.02223 \\
\hline 8 & 4.20 & 1.80 & 0.00158 & 0.00676 & 47.11 & 316.4 & 0.02977 & 0.01952 & 0.01407 \\
\hline 9 & 4.82 & 1.97 & 0.00146 & 0.00863 & 50.00 & 302.9 & 0.02964 & 0.02085 & 0.01585 \\
\hline 10 & 4.68 & 2.03 & 0.00096 & 0.00842 & 38.77 & 246.2 & 0.02995 & 0.02169 & 0.01640 \\
\hline 11 & 4.07 & 2.18 & 0.00231 & 0.00511 & 45.46 & 270.2 & 0.04005 & 0.02552 & 0.01643 \\
\hline 12 & 4.92 & 1.98 & 0.00235 & 0.00640 & 60.67 & 235.6 & 0.03926 & 0.02795 & 0.02052 \\
\hline 13 & 10.3 & 0.54 & 0.00190 & 0.01589 & 69.84 & 688.3 & 0.03202 & 0.02457 & 0.01954 \\
\hline 14 & 4.10 & 2.28 & 0.00183 & 0.00583 & 42.96 & 207.7 & 0.04010 & 0.02624 & 0.01760 \\
\hline 15 & 4.54 & 2.85 & 0.00177 & 0.00684 & 50.58 & 318.8 & 0.03277 & 0.02159 & 0.01535 \\
\hline 16 & 3.81 & 2.45 & 0.00233 & 0.00419 & 46.25 & 178.7 & 0.04469 & 0.02909 & 0.01867 \\
\hline 17 & 6.86 & 2.83 & 0.00210 & 0.00821 & 41.58 & 250.3 & 0.04536 & 0.03140 & 0.02226 \\
\hline 18 & 3.92 & 1.75 & 0.00044 & 0.00709 & 8.66 & 225.3 & 0.03195 & 0.01601 & 0.01294 \\
\hline 19 & 3.80 & 1.54 & 0.00085 & 0.00684 & 37.34 & 289.7 & 0.02453 & 0.01639 & 0.01214 \\
\hline 20 & 3.96 & 2.26 & 0.00311 & 0.00467 & 57.77 & 258.8 & 0.03962 & 0.02626 & 0.01752 \\
\hline 21 & 4.54 & 2.37 & 0.00239 & 0.00708 & 61.06 & 227.7 & 0.03688 & 0.02592 & 0.01885 \\
\hline 22 & 5.83 & 2.09 & 0.00189 & 0.00956 & 60.74 & 395.8 & 0.03117 & 0.02229 & 0.01668 \\
\hline 23 & 4.00 & 1.74 & 0.00135 & 0.00753 & 39.46 & 287.9 & 0.02887 & 0.01880 & 0.01345 \\
\hline 24 & 4.37 & 2.33 & 0.00187 & 0.00701 & 50.39 & 210.7 & 0.03778 & 0.02563 & 0.01820 \\
\hline 25 & 4.25 & 2.47 & 0.00243 & 0.00433 & 54.81 & 226.0 & 0.04324 & 0.02837 & 0.01914 \\
\hline 26 & 4.35 & 2.07 & 0.00167 & 0.00619 & 49.69 & 268.7 & 0.03346 & 0.02292 & 0.01638 \\
\hline 27 & 3.69 & 2.00 & 0.00089 & 0.00586 & 26.94 & 187.2 & 0.03546 & 0.02230 & 0.01530 \\
\hline 28 & 4.97 & 2.22 & 0.00143 & 0.00775 & 60.55 & 258.6 & 0.03176 & 0.02357 & 0.01818 \\
\hline 29 & 5.49 & 2.20 & 0.00158 & 0.00981 & 53.77 & 309.3 & 0.03166 & 0.02353 & 0.01790 \\
\hline 30 & 4.32 & 1.82 & 0.00133 & 0.00641 & 45.70 & 314.4 & 0.02998 & 0.01958 & 0.01421 \\
\hline 31 & 4.47 & 1.61 & 0.00135 & 0.00674 & 43.82 & 425.9 & 0.02828 & 0.01739 & 0.01216 \\
\hline 32 & 5.06 & 1.98 & 0.00123 & 0.00786 & 46.68 & 326.1 & 0.03156 & 0.02058 & 0.01550 \\
\hline 33 & 4.93 & 2.70 & 0.00154 & 0.00684 & 47.23 & 192.4 & 0.04325 & 0.02967 & 0.02154 \\
\hline 35 & 4.41 & 2.07 & 0.00268 & 0.00617 & 68.62 & 322.0 & 0.03329 & 0.02259 & 0.01625 \\
\hline 36 & 4.51 & 1.99 & 0.00167 & 0.00722 & 51.61 & 294.2 & 0.03113 & 0.02142 & 0.01585 \\
\hline
\end{tabular}

Water uptake extrapolated to equilibrium (for explanation, see below in the section: Determination of "infinite" water uptake) using the Solver software and the PEK model

$d m / d t$ derivative of weight gain

friction of the material with the steel. This harsh condition at industrial scale results in a lower MC in the pellets as compared to the pilot plant process, and these pellets are likely to reabsorb moisture faster than the pellets with higher initial moisture content. The initial rate of water up-take might be important in order to explain fast temperature increases in pellet storage.

\subsection{Water uptake, heat of condensation and potential temperature rise}

Thermal conductivity and specific heat capacity in wood pellets are important properties in estimating the temperature gain in wood pellets as a consequence of water condensation/ absorption driven by changes in $\mathrm{RH} \%$, spread of the heat in the pellet bulk as well as modelling and understanding the 
Table 3 Water uptake by pellet batches produced

\begin{tabular}{lllll}
\hline Raw material & Mean $(\%)$ & sd & RSD & $\mathrm{n}$ \\
\hline Pine (P) & 4.36 & 0.41 & 9.4 & 14 \\
Spruce (S) & 4.66 & 0.45 & 9.6 & 6 \\
Pine/spruce mix (PS) & 4.48 & 0.31 & 6.9 & 8 \\
Straw & 6.32 & - & - & 2 \\
Eucalyptus & 4.95 & 0.88 & 17.8 & 2 \\
Wine pruings/pomace & 10.33 & - & - & 1 \\
Torrefied pine & 7.00 & - & - & 2 \\
P+S + PS & 4.61 & 0.63 & 13.7 & 28 \\
All types & 4.73 & 1.16 & 24.5 & 35 \\
Production & & & & \\
Industry & 4.61 & 0.74 & 16.1 & 17 \\
Pilot plant & 4.84 & 1.44 & 29.7 & 18 \\
\hline
\end{tabular}

Grouped according to raw materials used and production scale (industry/pilot plant)

self-heating processes in a pellet storage silo (Sjöström and Blomqvist 2014). In an investigation by Guo et al. (2013), three different pellet batches were studied with a MC ranging from 4.6 to 8.8 (Hartley and Wood 2008). From experimental data they estimated the values of the thermal conductivity and specific heat capacity of the pellets, from which they constructed the following model equation:

$\lambda_{\text {eff }}=(0.219+0.01 \mathrm{MC}) \times(1-\phi)+\phi \times 0.027$

where $\lambda_{e f f}$ is the effective thermal conductivity of the packed bed in $\mathrm{W} /(\mathrm{m} \mathrm{K})$ and $\varphi$ is the porosity in fraction; MC is the moisture content in percentage, wet based

and

$C_{P}=1.01+0.032 \mathrm{MC}$ where $C_{P}$ is the specific heat capacity for pellets in $\mathrm{kJ} / \mathrm{kg} \mathrm{K}$ and $\mathrm{MC}$ is the moisture content. The number 1.01 was their experimentally found mean for $\left(C_{P, \text { dry }}\right)($ Guo et al. 2013) and was used in the present study as a reasonable approximation.

In the present study, the following calculations were made for the various pellet batches (results from 34 samples were used, excluding Batch 13 as an outlier);

- the mean porosity $\phi$ (air space between the pellets in bulk) was calculated from pellet bulk density and single pellet density, to be 0.471 (range $0.415-0.557$, RSD $6.4 \%$,) and

- the mean pellet MC at $40 \%$ RH was $7.53 \%$ (range 6.58 $8.65 \%$, RSD $6.52 \%$ ).

These values were used to:

- calculate the effective thermal conductivity $\lambda_{\text {eff }}$ (Eq. 2), using the DVS registered moisture uptake, to be $0.153 \mathrm{~W} /$ $\mathrm{m} \cdot \mathrm{K}$ (range $0.129-0.171 \mathrm{~W} / \mathrm{m} \cdot \mathrm{K}$, RSD $5.5 \%$ ) over the $\mathrm{MC}$ range. This value is in the same range as was reported in the literature $(0.146-0.192 \mathrm{~W} / \mathrm{m} \cdot \mathrm{K})$ (Guo et al. 2013).

- estimate the specific heat capacity $C_{P}$ at RH $40 \%$ (Eq. 3), to be $1.16 \mathrm{~kJ} / \mathrm{kg} \mathrm{K}$ (range 1.13-1.23 kJ/kg K, RSD 1.8\%, $\mathrm{MC}$ range $6.58-8.65 \%$ w.b.) as compared to the literature data $\left(1.074-1.253 \mathrm{~kJ} / \mathrm{kg} \mathrm{K}\right.$, temp. range $25-50{ }^{\circ} \mathrm{C}, \mathrm{MC}$ range $1.4-9.0 \%$ w.b.) (Guo et al. 2013).

In order to make an estimation of the potential heat release (when raising the $\mathrm{RH} \%$ from 40 to $80 \%$ ), the total water uptake was taken into account, $4.56 \%$ (Table 2, range $3.69-6.86 \%$, RSD 14.3\%) and an approximate heat
Fig. 2 Water uptake at $80 \mathrm{RH} \%$ for the sample of Batch 2, corresponding to $4.32 \%$ based on the sample weight at $\mathrm{RH} 40 \%$. Observed DVS data $(\mathrm{O})$, for clearness; at 0-100 min every 20th observation is shown, 100-200 min every 40th and at 200-min every 80th. Fitted PEK model equation (- - ), PEK equation separated in fast $(-)$ and slow $(\bullet \bullet \bullet \bullet)$ processes

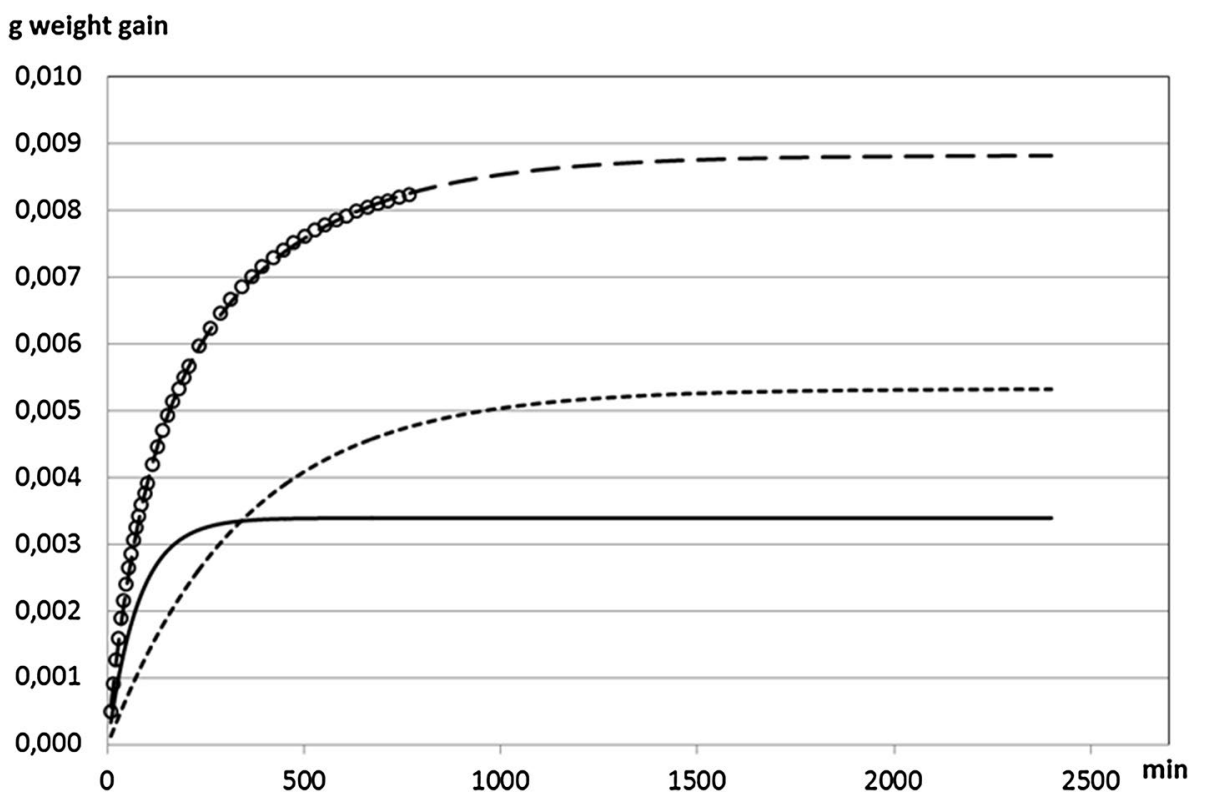


Fig. 3 Water uptake rate expressed as derivative of weight-gain $(\mathrm{dm} / \mathrm{dt})$ at 10,30 and $60 \mathrm{~min}$, (Confidence intervals are shown. For the method variation, see Sect. 3.2.) Batch 16 (square) pine. Total water uptake $3.81 \%$ (Industry); Batch 7 (diomend) wheat straw. Total water uptake $5.77 \%$ (Industry); Batch 18 (triangle) pine/spruce mixture. Total water uptake 3.92\% (Pilot plant); Batch 19 (circle) torrefied pine. Total water uptake $3.80 \%$ (Pilot plant)

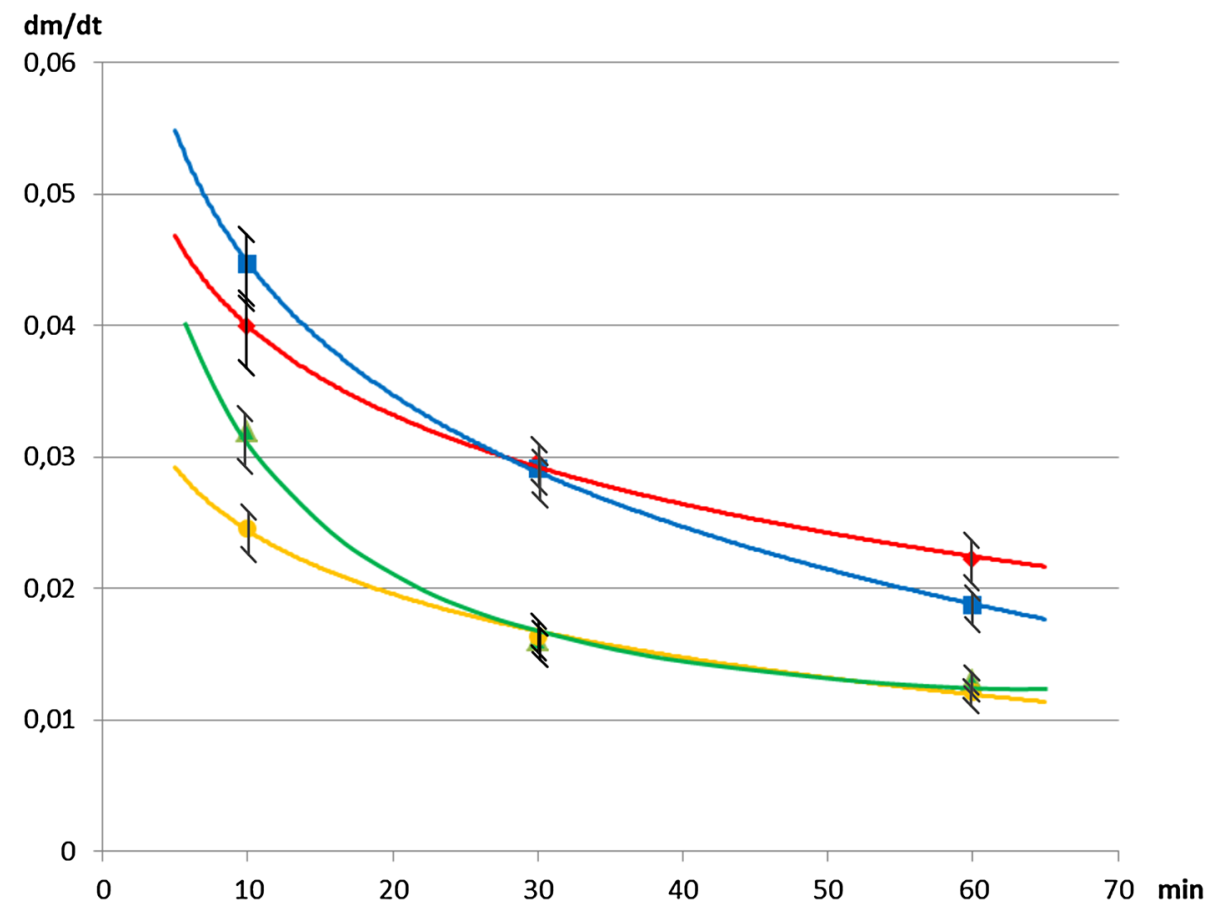

of condensation value of $2200 \mathrm{~kJ} / \mathrm{kg}$ water was used. The slight change in $C_{P}$ at different temperatures was not taken into account in this estimation.

- This (water uptake/heat of condensation) gives an estimation that a heat release of $100 \mathrm{~kJ} / \mathrm{kg}$ pellets (range $81-151 \mathrm{~kJ} / \mathrm{kg}$, RSD 14.3\%) would be possible and a potential temperature increase (heat release $/ C_{P}$ ) of $87^{\circ} \mathrm{C}$ (range $72-169$, RSD 12.2).

However, at the same time there will be loss of energy to the outside of the bulk as radiant heat on the surface and by conductivity in the bulk. The actual temperature increase will be balanced by these two effects. However, the first hours after an increase in $\mathrm{RH} \%$ should be expected to be most critical if the first initial $2 \mathrm{~h}$ after a drastic change in $\mathrm{RH} \%$ are included in the estimation and the loss of energy from the bulk is considered limited during this time. The water condensed is likely to re-volatilise due to the heat and after diffusion re-condense in cooler parts of the pellet bulk and thus, cause a "moving" heated zone as observed by pellet disintegration in the centre of the bulk after self-heating incidents (Obernberger and Thek 2010). This water transport will again lower the pellet humidity in parts of the storage closer to the outer parts of the bulk and make them sorb additional water from the air.

- Thus, the water uptake during the first $2 \mathrm{~h}$ at RH $80 \%$ was determined to be $2.15 \%$ (Table 2 , range $1.54-2.85 \%$, RDS $15.2 \%$ ), corresponding to $48 \%$ of the infinite water uptake at $80 \mathrm{RH} \%$, resulting in a potential heat release of $47 \mathrm{~kJ} / \mathrm{kg}$ (range 12-63 kJ/kg, RSD 15.2\%) and temperature rise of $45^{\circ} \mathrm{C}$ (range $12-58{ }^{\circ} \mathrm{C}$, RSD 14\%).

Even if this is a rough estimation, not taking all material properties (raw material, pellet size, etc.) into account and not including the dynamics in the process, it clearly demonstrates that the potential temperature rise is considerable and might cause self-heating problems during storage. As a comparison, temperature rise up to $55^{\circ} \mathrm{C}$ in a ca. 12 tones pellets pile has been reported previously (Arshadi et al. 2009). The actual temperature reached in a silo locally and under specific conditions is however very complicated to calculate. Additional factors influencing the heat accumulation and potential risk of self-ignition are also depending on the physical surroundings affected by the construction of the silo/storage in question; size and insulation, ventilation, etc. on the temperature accumulation. The actual change in relative air humidity/temperature, ventilation, size and insulation of the storage are likely to play an important role; all factors contributing to make a full modelling very complicated.

In addition, the increase in temperature caused by condensation will also increase the reaction rate of the exothermal autoxidation of unsaturated fatty acids (Litwinienko 2001; Juita et al. 2012). The correlation between the autoxidation process and the produced gases during off-gassing from fuelpellets mentioned above have recently been confirmed (Attard et al. 2016; Arshadi et al. 2009). This temperature increase will increase the autoxidation reaction rate and further add to the temperature rise. The combustible volatiles produced 
(aldehydes/ketones, $\mathrm{CO}, \mathrm{CH}_{4}$ ) together with remaining terpenes and/or other combustible gases from the bulk will contribute to the potential for a self-heating incident to result in a fire.

\section{Conclusion}

The DVS technique applied to fuel pellet samples gives information on specific fuel pellet batches regarding their water uptake properties in air humidity/temperature conditions that cause condensation. From the results it can be concluded that:

- The heat of condensation released during water condensation in a pellet silo has a potential to considerably contribute to increasing the temperature, especially in a situation with a fast and/or large change in relative air humidity, and should be expected to be a major contributing factor to initiating temperature increase incidents. The correlation between water uptake and heat release of lignocellulosic material is a well-known process (Back and Johansson 1990; Back 1981). In addition, such a temperature rise can be expected to contribute to the initiation and acceleration of autoxidation.

- The water uptake between pellets made from pine, spruce and pine/spruce mixtures did not differ significantly but was higher for batches made from wine prunings/pomace, straw and torrefied pine (although these types of samples were few).

- The water uptake rate $(\mathrm{dm} / \mathrm{dt})$ in the initial part of the process gives an indication of the potential for a fast temperature rise associated with changes in air relative humidity and the following condensation in pellet storage. The uptake rate varies considerably between the pellet samples made from different raw materials.

- From the potential water uptake it is possible to calculate a heat release potential due to heat of condensation and to make an estimation of potential local temperature rise. In addition, this implies that the different batches have varying potential to release heat of condensation and initiate/ accelerate a self-heating process in a silo.

- Thus, DVS analysis has the potential to complement other physical/chemical measurements on fuel pellets in predicting how the choice of fuel raw material and pellet processing parameters might influence the potential risk for self-heating, off-gassing and fire incidents.

- The results are based on a fairly large and representative number of fuel pellet batches on the European market and should provide a strong basis in modelling physical/ chemical processes in pellet storage. Such further studies have the potential to give a tool to predict the self-heating potential of various pellet batches. Such a tool should increase the possibility to reduce the risks associated with pellets storage/transportation and to avoid the conditions/situations involving highest risk for off-gassing, oxygen depletion and uncontrolled heat formation/fire.

Acknowledgements Annett Pollex and Jan Khalsa, at DBFZ pilot plant (Germany) and Waltraud Emhofer at BE2020 (Austria) for help with pellets production. Tobias Tengel, Carina Jonsson, Gunnar Kalén and Markus Segerström for experimental assistance. Financial support from Kempe Stiftelserna, Sweden and SafePellets (European project, grant agreement number 287026), Cost Action EUBIS TD1203. The Swedish Energy Agency for financial support of project Pelletplattformen 2, and PELS project no. 20569-4. Andrew Hunt and Thomas Attard for help with Supercritical extractions at The University of York, UK.

Open Access This article is distributed under the terms of the Creative Commons Attribution 4.0 International License (http://creativeco mmons.org/licenses/by/4.0/), which permits unrestricted use, distribution, and reproduction in any medium, provided you give appropriate credit to the original author(s) and the source, provide a link to the Creative Commons license, and indicate if changes were made.

\section{References}

Arshadi M, Gref R (2005) Emission of volatile organic compounds from softwood pellets during storage. For Prod J 55(12):132-135

Arshadi M, Geladi P, Gref R, Fjällström P (2009) Emission of volatile aldehydes and ketones from wood pellets under controlled conditions. Ann Occup Hyg 53(8):797-805. https://doi.org/10.1093/ annhyg/mep058

Ashman JM, Jones JM, Williams A (2018) Some characteristics of the self-heating of the large scale storage of biomass. Fuel Process Technol 174:1-8. https://doi.org/10.1016/j.fuproc.2018.02.004

Attard TM, Arshadi M, Nilsson C, Budarin VL, Valencia-Reyes E, Clark JH, Hunt AJ (2016) Impact of supercritical extraction on solid fuel wood pellet properties and off-gassing during storage. Green Chem. https://doi.org/10.1039/C5GC02479J

Back E (1981) Auto-ignition in hygroscopic, organic materials-Especially forest products- as initiated by moiture absorption from the ambient atmosphere. Fire Saf J 4:185-196

Back E, Johanson F (1990) The rate of isothermal heat evolution between $150{ }^{\circ} \mathrm{C}$ and $230{ }^{\circ} \mathrm{C}$ of lignocellulosic sheet materials in an air stream. I Princ Exp Results Holzforschung 44(1):21-30. https://doi.org/10.1515/hfsg.1990.44.1.21

Blomqvist P, Persson B (2003) Spontaneous ignition of biofuelsa literature survey of theoretical and experimental methods. SP Swedish National Testing and Research Institute, SP 2003, p 18

Blomqvist P, Persson H (2008) Self-heating in storages of wood pellets. In: Proceedings of the world bioenergy conference and exhibition on biomass for energy, Jonkoping, Sweden, May 2008, pp 27-29

Fan C, Bi XT (2013) Development of off-gas emission kinetics for stored wood pellets. Ann Occup Hyg 57(1):115-124. https://doi. org/10.1093/annhyg/mes037

Filbakk T, Skjevrak G, Høibø O, Dibdiakova J, Jirjis R (2011) The influence of storage and drying methods for Scots pine raw material on mechanical pellet properties and production parameters. Fuel Process Technol 92(5):871-878. https://doi.org/10.1016/j. fuproc.2010.12.001

Graham S, Ogunfayo I, Hall MR, Snape C, Quick W, Weatherstone $S$, Eastwick C (2016) Changes in mechanical properties of wood pellets during artificial degradation in a laboratory environment. 
Fuel Process Technol 148:395-402. https://doi.org/10.1016/j. fuproc.2016.03.020

Graham S, Eastwick C, Snape C, Quick W, Weatherstone S (2017) Mechanical degradation of biomass wood pellets during long term stockpile storage. Fuel Process Technol 160:143-151

Granström KM (2009) Emissions of sesquiterpenes from spruce sawdust during drying. Eur J Wood Prod 67(3):343-350. https://doi. org/10.1007/s00107-009-0325-1

Granström KM (2010) Underestimation of terpene exposure in the Nordic wood industry. J Occup Environ Hyg 7(3):144-151. https ://doi.org/10.1080/15459620903476330

Guo W, Lim CJ, Bi X, Sokhansanj S, Melin S (2013) Determination of effective thermal conductivity and specific heat capacity of wood pellets. Fuel 103:347-355. https://doi.org/10.1016/j. fuel.2012.08.037

Hartley ID, Wood LJ (2008) Hygroscopic properties of densified softwood pellets. Biomass Bioenerg 32(1):90-93

Hemingway RW, Nelson PJ, Hillis WE (1971) Rapid oxidation of the fats and resins in Pinus radiata chips for pitch contro. Tappi 54:95-98

Hill CAS, Norton AJ, Newman G (2010) The water vapour sorption properties of Sitka spruce determined using a dynamic vapour sorption apparatus. Wood Sci Technol 44(3):497-514

Hyttinen M, Masalin-Weijo M, Kalliokoski P, Pasanen P (2010) Comparison of VOC emissions between air-dried and heattreated Norway spruce (Picea abies), Scots pine (Pinus sylvesteris) and European aspen (Populus tremula) wood. Atmos Environ 44(38):5028-5033. https://doi.org/10.1016/j.atmos env.2010.07.018

Jirjis R (1995) Storage and drying of wood fuel. Biomass Bioenerg 9(1):181-190. https://doi.org/10.1016/0961-9534(95)00090-9

Juita, Dlugogorski BZ, Kennedy EM, Mackie JC (2012) Mechanism of formation of volatile organic compounds from oxidation of linseed oil. Ind Eng Chem Res 51(16):5653-5661. https://doi. org/10.1021/ie202536n

Koppejan J, Lönnermark A, Persson H, Larsson I, Blomqvist P, Arshadi M, Valencia-Reyes E, Melin S, Howes P, Wheeler P, Baxter D, Nikolaisen L (2013) Health and safety aspects of solid biomass storage, transportation and feeding. (Report). IEA Bioenergy. Produced by IEA Bioenergy Task 32, 36, 37 and 40 May 2013. https ://www.ieabioenergy.com/publications/health-and-safety-aspec ts-of-solid-biomass-storage-transportation-and-feeding/

Korber M, Hoffart V, Walther M, Macrae RJ, Bodmeier R (2010) Effect of unconventional curing conditions and storage on pellets coated with Aquacoat ECD. Drug Dev Ind Pharm 36(2):190-199. https ://doi.org/10.3109/03639040902882314

Kuang X, Shankar TJ, Bi XT, Sokhansanj S, Lim CJ, Melin S (2008) Characterization and kinetics study of off-gas emissions from stored wood pellets. Ann Occup Hyg 52(8):675-683. https://doi. org/10.1093/annhyg/men053

Kuang X, Shankar TJ, Bi XT, Lim CJ, Sokhansanj S, Melin S (2009a) Rate and peak concentrations of off-gas emissions in stored wood pellets-sensitivities to temperature, relative humidity, and headspace volume. Ann Occup Hyg 53(8):789-796. https://doi. org/10.1093/annhyg/mep049

Kuang X, Shankar TJ, Sokhansanj S, Lim CJ, Bi XT, Melin S (2009b) Effects of headspace and oxygen level on off-gas emissions from wood pellets in storage. Ann Occup Hyg 53(8):807-813. https:// doi.org/10.1093/annhyg/mep071

Larsson SH, Samuelsson R (2017) Prediction of ISO 17831-1:2015 mechanical biofuel pellet durability from single pellet characterization. Fuel Process Technol 163(Supplement C):8-15. https:// doi.org/10.1016/j.fuproc.2017.04.004

Larsson SH, Lestander TA, Crompton D, Melin S, Sokhansanj S (2012) Temperature patterns in large scale wood pellet silo storage. Appl Energy 92:322-327. https://doi.org/10.1016/j.apene rgy.2011.11.012

Litwinienko G (2001) Autooxidation of unsaturated fatty acids and their Esters. J Therm Anal Calorim 65(2):639-646. https://doi. org/10.1023/a:1017974313294

Miura K (2016) Adsorption of water vapor from ambient atmosphere onto coal fines leading to spontaneous heating of coal stockpile. Energy Fuels 30(1):219-229. https://doi.org/10.1021/acs.energ yfuels.5b02324

Morton WE, Hearle JWS (1997) Physical properties of textile fibres. The Textile institute, Manchester

Obernberger I, Thek G (2010) The pellet handbook. The production and thermal utilisation of biomass pellets. Earthscan Ltd, London, UK. ISBN: 978-1-84407-631-4

Okubayashi S, Griesser UJ, Bechtold T (2004) A kinetic study of moisture sorption and desorption on lyocell fibers. Carbohyd Polym 58(3):293-299. https://doi.org/10.1016/j.carbpol.2004.07.004

$\mathrm{Pa}$ A, Bi XT (2010) Modeling of off-gas emissions from wood pellets during marine transportation. Ann Occup Hyg 54(7):833-841. https://doi.org/10.1093/annhyg/meq049

Popescu C-M, Hill CAS, Anthony R, Ormondroyd G, Curling S (2015) Equilibrium and dynamic vapour water sorption properties of biochar derived from apple wood. Polym Degrad Stab 111:263-268. https://doi.org/10.1016/j.polymdegradstab.2014.10.014

Rupar-Gadd K (2006) Biomass pre-treatment for the production of sustainable energy: emissions and self-ignition. Doctoral thesis, Linne University, Serie Acta Wexionensia, ISSN 1404-4307; 88; URN:urn:nbn:se:vxu:diva-510; ISBN: 91-7636-501-8

Safepellets Project, European project, grant agreement number 287026. http://www.safepellets.eu/. Accessed 15 Dec 2017

Sjöström J, Blomqvist P (2014) Direct measurements of thermal properties of wood pellets: elevated temperatures, fine fractions and moisture content. Fuel 134:460-466. https://doi.org/10.1016/j. fuel.2014.05.088

Stelte W, Sanadi AR, Shang L, Holm JK, Ahrenfeldt J, Henriksen UB (2012) Recent developments in biomass pelletization: a review. BioResources 7(3):4451-4490

Stratev D, Gradinger C, Ters T, Fackler K, Kuncinger T, Srebotnik E (2011) Fungal pretreatment of pine wood to reduce the emission of volatile organic compounds. Holzforschung 65(4): https://doi. org/10.1515/hf.2011.078

Svedberg URA, Högberg HE, Högberg J, Galle B (2004) Emission of hexanal and carbon monoxide from storage of wood pellets, a potential occupational and domestic health hazard. Ann Occup Hyg 48(4):339-349. https://doi.org/10.1093/annhyg/meh015

Svedberg U, Samuelsson J, Melin S (2008) Hazardous off-gassing of carbon monoxide and oxygen depletion during ocean transportation of wood pellets. Ann Occup Hyg 52(4):259-266. https://doi. org/10.1093/annhyg/men013

Svedberg U, Petrini C, Johanson G (2009) Oxygen depletion and formation of toxic gases following sea transportation of logs and wood chips. Ann Occup Hyg 53(8):779-787. https://doi. org/10.1093/annhyg/mep055

Xie Y, Hill CAS, Jalaludin Z, Curling SF, Anandjiwala RD, Norton AJ, Newman G (2011a) The dynamic water vapour sorption behaviour of natural fibres and kinetic analysis using the parallel exponential kinetics model. J Mater Sci 46(2):479-489

Xie Y, Hill CAS, Xiao Z, Mai C, Militz H (2011b) Dynamic water vapour sorption properties of wood treated with glutaraldehyde. Wood Sci Technol 45(1):49-61

Publisher's Note Springer Nature remains neutral with regard to jurisdictional claims in published maps and institutional affiliations. 